\title{
Strategic Weight Manipulation in Multiple Attribute Decision Making in an Incomplete Information Context
}

\author{
Yating Liu, Yucheng Dong \\ Business School, Sichuan \\ University, Chengdu, China \\ yatingliu@stu.scu.edu.cn \\ ycdong@stu.scu.edu.cn
}

\author{
Francisco Chiclana \\ Centre for Computational \\ Intelligence, De Montfort University, \\ Leicester, UK \\ chiclana@dmu.ac.uk
}

\author{
Francisco Javier Cabrerizo, \\ Enrique Herrera-Viedma \\ DECSAI, University of Granada, \\ Granada, Spain \\ \{cabrerizo,viedma\}@,decsai.ugr.es
}

\begin{abstract}
In some real-world multiple attribute decision making (MADM) problems, a decision maker can strategically set attribute weights to obtain her/his desired ranking of alternatives, which is called the strategic weight manipulation of the MADM. Sometimes, the attribute weights are given with imprecise or partial information, which is called incomplete information of attribute weights. In this study, we propose the strategic weight manipulation under incomplete information on attributes weights. Then, a series of mixed 0-1 linear programming models (MLPMs) are proposed to derive a strategic weight vector for a desired ranking of an alternative. Finally, a numerical example is used to demonstrate the validity of our models
\end{abstract}

Keywords-multiple attribute decision making; strategic weight manipulation; ranking; incomplete information

\section{INTRODUCTION}

Multiple attribute decision making (MADM) refers to the problem of ranking alternative based on the evaluation information of alternatives associated with multiple attributes $[14,29]$. MADM has been widely used in many fields including engineering, technology, economy, management and military [6, 12, 22, 32].

The attribute weights play an important role in MADM problems. In the existing literature, there are several approaches to obtain the attribute weights from the decision maker's preference information on the set of attributes [1, 7, $15,18,25,27]$. However, sometimes, decision makers might find difficult to provide precise attribute weights because of time pressure and limited expertise in regards to the problem domain, which could result in incomplete information of attribute weights.

Decision makers may express their opinions dishonestly to favor their own interest, which is generally known as strategic manipulation or non-cooperative behaviors $[11,13$, 23, 26, 30, 31]. Thus, the strategic weight manipulation problem in which a decision maker may strategically set attribute weights in order to obtain her/his desired ranking of

This work was supported in part by the NSF of China under Grant 71571124. the alternatives in the process of setting attribute weights in a MADM problem is worth dealing with.

Although there exists numerous approaches to set attribute weights $[1,7,15,18,25,27]$, it is also true that the general theoretical framework that governs the strategic weight manipulation is not always considered. In this study, we define the concept of ranking range of an alternative in MADM under incomplete information of attribute weights. Then, a series of mixed 0-1 linear programming models (MLPMs) are proposed to derive a strategic weight vector by manipulating the decision makers' attribute weights under their given incomplete information.

The rest of this paper is organized as follows. Section 2 provides the basic MADM concepts and the description of the proposed strategic weight manipulation problem under incomplete information of attribute weights. Section 3 proposes mixed 0-1 linear programming models to obtain the ranking range of an alternative and a strategic weight vector to manipulate the ranking of an alternative under incomplete information. Section 4 provides a numerical example that shows the validity of the proposed models. Finally, Section 5 concludes the study.

\section{PRELIMINARIES}

This section introduces the basic concepts regarding MADM problem, incomplete information of attribute weights, and the proposed strategic weight manipulation problem as needed for the rest of the paper.

\section{A. MADM problem}

Let $X=\left\{x_{1}, \ldots, x_{n}\right\}$ be the set of alternatives, $A=\left\{a_{1}, \ldots, a_{m}\right\}$ the set of predefined attributes, and $w=\left(w_{1}, w_{2}, \ldots, w_{m}\right)$ the associated weight vector of the attributes, such that $w_{j} \geq 0$ and $\sum_{j=1}^{m} w_{j}=1$.

Let $V=\left[v_{i j}\right]_{n \times m}$ be the decision matrix given by the decision maker, where $v_{i j}$ is the preference value for the 
alternative $x_{i} \in X$ with respect to the attribute $a_{j} \in A$, representing how well alternative $x_{i}$ verifies attribute $a_{j}$. Generally, the resolution process of a MADM problem includes two steps [6, 12, 14, 22, 29, 32]:

(1) Normalization of the decision matrix. The decision matrix $V=\left[v_{i j}\right]_{n \times m}$ is transformed into its corresponding standardized decision matrix form $\bar{V}=\left[\bar{v}_{i j}\right]_{h \times m}:$

(i) If $a_{j} \in A$ is a benefit attribute

$$
\bar{v}_{i j}=\frac{v_{i j}-\min _{i}\left(v_{i j}\right)}{\max _{i}\left(v_{i j}\right)-\min _{i}\left(v_{i j}\right)}
$$

(ii) If $a_{j} \in A$ is a cost attribute

$$
\bar{v}_{i j}=\frac{\max _{i}\left(v_{i j}\right)-v_{i j}}{\max _{i}\left(v_{i j}\right)-\min _{i}\left(v_{i j}\right)}
$$

(2) Aggregation of the standardized decision matrix and ranking of alternatives. In this study, we use a weighted average (WA) operator as the decision evaluation function, $D\left(x_{i}\right)$ :

$$
D\left(x_{i}\right)=W A_{w}\left(\bar{v}_{i 1}, \bar{v}_{i 2}, \ldots, \bar{v}_{i m}\right)=\sum_{j=1}^{m} w_{j} \bar{v}_{i j}
$$

Alternatives are ranked according to their evaluation value. Let $Q_{k}=\left\{x_{i} \mid D\left(x_{i}\right)>D\left(x_{k}\right), i=1,2, \ldots, n\right\}$ be the set alternatives whose decision evaluation value is greater than that of alternative $x_{k}$, and let $\left|Q_{k}\right|$ be its cardinality. Because $x_{k} \notin Q_{k}$, then the following definition of the ranking position of an alternative is justified:

$$
r\left(x_{k}\right)=\left|\left\{x_{i} \mid D\left(x_{i}\right)>D\left(x_{k}\right), \quad i=1,2, \ldots, n\right\}\right|+1 .
$$

Let $r_{w}\left(x_{k}\right)$ be the ranking of alternative $x_{k}$ obtained when the weight vector of the attributes $w=\left(w_{1}, w_{2}, \ldots, w_{m}\right)$ is used in Eq. (3). Notice that $r_{w}\left(x_{k}\right)$ can change when the weight vector $w=\left(w_{1}, w_{2}, \ldots, w_{m}\right)$ changes, and consequently a manipulation of the weight vector could lead to a change in the ranking order of the alternatives.

\section{B. Incomplete information of attribute weights}

As mentioned before, in MADM problems, decision makers could provides incomplete attribute weights information, which can be modeled using one of the following representation formats $[19,24]$ :

- Weak ranking:

$$
W R=\left\{w_{i} \geq w_{j} \geq 0 ; i \neq j\right\}
$$

- Strict ranking:

$$
S R=\left\{w_{i}-w_{j} \geq \alpha_{i} ; i \neq j ; w_{i}, w_{j} \geq 0\right\}
$$

- Ranking multiples:

$$
R M=\left\{w_{i} \geq \beta_{i} w_{j}, i \neq j, w_{i} \geq 0, w_{j} \geq 0\right\}
$$

- Interval form:

$$
I=\left\{\gamma_{i} \leq w_{i} \leq \gamma_{i}+\varepsilon_{i}\right\}
$$

- Ranking differences:

$$
R D=\left\{w_{i}-w_{j} \geq w_{k}-w_{i} ; i \neq j \neq k ; w_{i}, w_{j}, w_{k} \geq 0\right\}
$$

- Bounded:

$$
B=\left\{\theta_{i} \leq w_{i} / w_{j} \leq \theta_{i}+\varepsilon_{i}: w_{i}, w_{j} \geq 0\right\}
$$

In Eqs. (4)-(9), $\left\{\alpha_{i}\right\},\left\{\beta_{i}\right\},\left\{\gamma_{i}\right\},\left\{\varepsilon_{i}\right\}$ and $\left\{\theta_{i}\right\}$ are all assumed to be non-negative.

Let $S$ be the set of attribute weights subject to one or more of the Eqs. (4)-(9). Such set $S$ is referred to as a set of incomplete attribute weights. The following example illustrates three different sets $S$ of incomplete attribute weights.

Example 1: Assume three attributes $\left\{a_{1}, a_{2}, a_{3}\right\}$. The following are three possible sets of incomplete attribute weights information:

(1)

(2)

$S_{1}=\left\{\left(w_{1}, w_{2}, w_{3}\right)^{T} \mid w_{1} \geq w_{2} \geq w_{3}\right\}$

$S_{2}=\left\{\left(w_{1}, w_{2}, w_{3}\right)^{T} \mid w_{1}-w_{2} \geq w_{3}-w_{2}\right\}$

$S_{3}=\left\{\left(w_{1}, w_{2}, w_{3}\right)^{T} \mid w_{1} / w_{2} \geq 2, \quad w_{1} \geq w_{3}, \quad w_{2} \geq w_{3}\right\}$

\section{The proposed strategic weight manipulation problem}

Because different attribute weights may yield different ranking of alternatives, in the following the ranking range of alternatives for a set of incomplete attribute weights is proposed:

Definition 1: Let $S$ be a set of incomplete attribute weights for a given MADM problem, $r\left(x_{k}\right)=\min _{w \in S} r_{w}\left(x_{k}\right)$ and $\bar{r}\left(x_{k}\right)=\max _{w \in S} r_{w}\left(x_{k}\right)$ be the best and worst ranking of alternative $x_{k}$ for all possible incomplete attribute weights in $S$, respectively. Then $R\left(x_{k}\right)=\left[r\left(x_{k}\right), \bar{r}\left(x_{k}\right)\right]$ is called the ranking range of alternative $x_{k}$ for attribute weights set $S$.

In a MADM problem, a decision maker may be interested in finding out, and subsequently proposing, the attribute weight vector leading to her/his desired ranking of alternatives. This is referred to as the strategic weight manipulation in MADM under incomplete information of attribute weights set.

\section{STRATEGIC WEIGHT MANIPULATION}

In this section, we present mixed 0-1 linear programming models to obtain (A) the ranking range and (B) the strategic attribute weight vector to manipulate the ranking of an alternative.

\section{A. Ranking range}

Let $y_{i} \in\{0,1\}, M$ be a large enough number, and $D\left(x_{i}\right)$ as defined in Eq. (3). Then, we have:

Lemma 1: (i) $x_{i} \quad x_{k}$ if and only if $y_{i}=1$ under the conditions $D\left(x_{i}\right)>D\left(x_{k}\right)-\left(1-y_{i}\right) M$ and $D\left(x_{i}\right) \leq D\left(x_{k}\right)+y_{i} M$. 
(ii) $x_{i} \precsim x_{k}$ if and only if $y_{i}=0$ under the conditions $D\left(x_{i}\right) \leq D\left(x_{k}\right)+y_{i} M$ and $D\left(x_{i}\right)>D\left(x_{k}\right)-\left(1-y_{i}\right) M$.

The proof of Lemma 1 is provided in Appendix A.

Based on Lemma 1, the following mixed 0-1 linear programming models $(10-11)$ are proposed to obtain the ranking range $R=\left[\underline{r}\left(x_{k}\right), \bar{r}\left(x_{k}\right)\right]$ of the alternative $x_{k}$ a set of incomplete attribute weights $S$ :

$$
\begin{aligned}
& \underline{r}\left(x_{k}\right)=\min \sum_{i=1}^{n} y_{i}+1 \\
& \text { s.t. }\left\{\begin{array}{l}
\sum_{j=1}^{m} w_{j} \bar{v}_{i j}>\sum_{j=1}^{m} w_{j} \bar{v}_{k j}-\left(1-y_{i}\right) M, \quad(i=1,2, \ldots, n) \\
\sum_{j=1}^{m} w_{j} \bar{v}_{i j} \leq \sum_{j=1}^{m} w_{j} \bar{v}_{k j}+y_{i} M, \quad(i=1,2, \ldots, n) \\
y_{i}=1 \quad \text { or } \quad 0, \quad(i=1,2, \ldots, n) \\
\left(w_{1}, w_{2}, \ldots, w_{m}\right) \in S
\end{array}\right.
\end{aligned}
$$

and

$$
\begin{aligned}
& \bar{r}\left(x_{k}\right)=\max \sum_{i=1}^{n} y_{i}+1 \\
& \text { s.t. }\left\{\begin{array}{l}
\sum_{j=1}^{m} w_{j} \bar{v}_{i j}>\sum_{j=1}^{m} w_{j} \bar{v}_{k j}-\left(1-y_{i}\right) M, \quad(i=1,2, \ldots, n) \\
\sum_{j=1}^{m} w_{j} \bar{v}_{i j} \leq \sum_{j=1}^{m} w_{j} \bar{v}_{k j}+y_{i} M, \quad(i=1,2, \ldots, n) \\
y_{i}=1 \quad \text { or } \quad 0, \quad(i=1,2, \ldots, n) \\
\left(w_{1}, w_{2}, \ldots, w_{m}\right) \in S
\end{array}\right.
\end{aligned}
$$

\section{B. Strategic weight manipulation on an alternative}

Let $w_{0}=\left(w_{1}^{0}, w_{2}^{0}, \ldots, w_{m}^{0}\right)$ be the objective weight vector of the attributes in a MADM problem. Let $w=\left(w_{1}, w_{2}, \ldots, w_{m}\right) \in S$ be the decision maker's strategic weight vector to manipulate the ranking of alternative $x_{k}$.

It is natural that the decision maker wishes to minimize the difference between the objective and strategic weight vectors, i.e.,

$$
\min \sum_{j=1}^{m}\left|w_{j}-w_{j}^{0}\right|
$$

Let the decision maker's desired ranking of the alternative $x_{k}$ be $r^{*}\left(x_{k}\right)$, then the decision maker would like the following equality to hold

$$
r_{w}\left(x_{k}\right)=r^{*}\left(x_{k}\right)
$$

Based on Eqs (12) and (13), an optimization-based model to find out the decision maker's strategic weight is presented as follows.

$$
\left\{\begin{array}{l}
\min \sum_{j=1}^{m}\left|w_{j}-w_{j}^{0}\right| \\
\text { s.t. } \quad r_{w}\left(x_{k}\right)=r^{*}\left(x_{k}\right)
\end{array}\right.
$$

To obtain the optimum solution to model (14), the following notation is introduced: $b_{j}=w_{j}-w_{j}^{0}$ and $g_{j}=\left|w_{j}-w_{j}^{0}\right|$.

Model (14) can be transformed in the following equivalent mixed 0-1 linear programming model:

$$
\begin{aligned}
& \min \sum_{j=1}^{m} g_{j}
\end{aligned}
$$

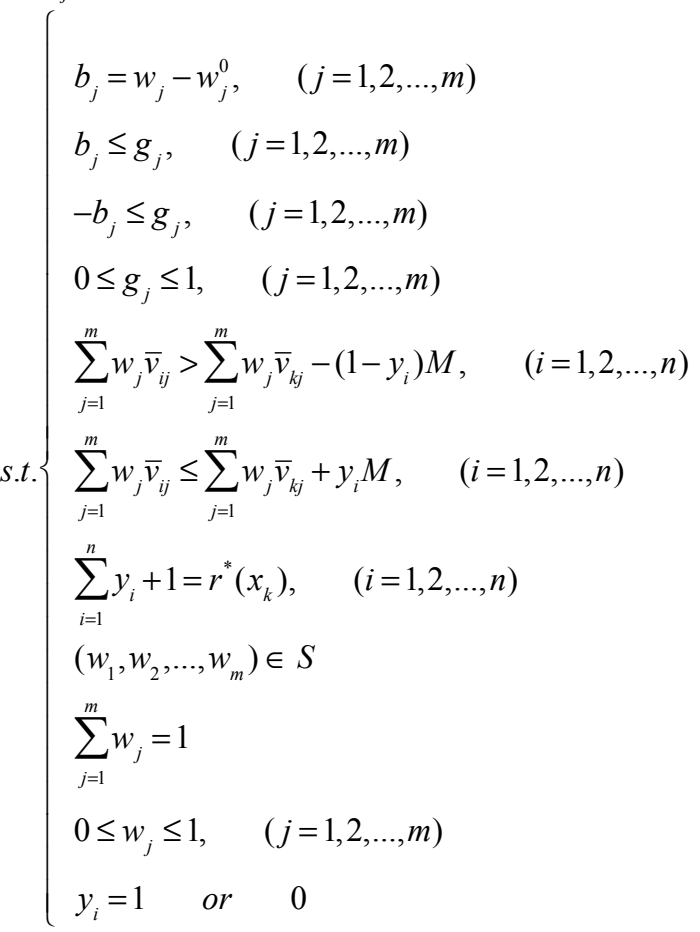

\section{NUMERICAL ANALYSIS}

Let us consider the following numerical example, with data provided in Appendix B, regarding the Academic Ranking of World Universities (http:/www.arwu.org/) to demonstrate the validity of the proposed models. In this example, the set of alternatives consists of 50 universities $\left\{x_{1}, x_{2}, \ldots, x_{50}\right\}$, which are ranked using their performance regarding the following set of 6 attributes:

$a_{1}$ : Quality of Education (Alumni of an institution winning Nobel Prizes and Fields Medals);

$a_{2}$ : Quality of Faculty 1 (Staff of an institution winning Nobel Prizes and Fields Medals);

$a_{3}$ : Quality of Faculty 2 (Highly cited researchers in 21 broad subject categories);

$a_{4}$ : Papers published in Nature and Science;

$a_{5}$ : Papers indexed in Science Citation Index-expanded and Social Science Citation Index;

$a_{6}$ : Per capita academic performance of an institution. 
First, the standardized decision matrix $\bar{V}=\left[\bar{v}_{i j}\right]_{50 \times 6}$ is obtained. Let $S=\left\{\left(w_{1}, w_{2}, \ldots, w_{6}\right)^{T} \mid w_{1} \geq w_{2} \ldots \geq w_{6}\right\}$, then using models (10-11) the ranking range of the alternatives $\left\{x_{1}, x_{2}, \ldots, x_{50}\right\}$ is obtained, $R$, and given in Table 1 .

Table 1: The ranking range $R$ for the 50 universities

\begin{tabular}{cccccl}
\hline$x_{i}$ & $R$ & $x_{i}$ & $R$ & $x_{i}$ & $R$ \\
\hline$x_{1}$ & {$[1,1]$} & $x_{2}$ & {$[2,11]$} & $x_{3}$ & {$[3,6]$} \\
\hline$x_{4}$ & {$[2,3]$} & $x_{5}$ & {$[3,5]$} & $x_{6}$ & {$[3,8]$} \\
\hline$x_{7}$ & {$[7,10]$} & $x_{8}$ & {$[7,11]$} & $x_{9}$ & {$[5,10]$} \\
\hline$x_{10}$ & {$[5,10]$} & $x_{11}$ & {$[10,11]$} & $x_{12}$ & {$[12,26]$} \\
\hline$x_{13}$ & {$[12,13]$} & $x_{14}$ & {$[14,36]$} & $x_{15}$ & {$[15,32]$} \\
\hline$x_{16}$ & {$[13,16]$} & $x_{17}$ & {$[15,28]$} & $x_{18}$ & {$[15,22]$} \\
\hline$x_{19}$ & {$[15,26]$} & $x_{20}$ & {$[14,28]$} & $x_{21}$ & {$[24,50[$} \\
\hline$x_{22}$ & {$[22,46]$} & $x_{23}$ & {$[16,45]$} & $x_{24}$ & {$[14,26]$} \\
\hline$x_{25}$ & {$[24,46]$} & $x_{26}$ & {$[25,44]$} & $x_{27}$ & {$[25,47]$} \\
\hline$x_{28}$ & {$[16,25]$} & $x_{29}$ & {$[23,32]$} & $x_{30}$ & {$[27,44]$} \\
\hline$x_{31}$ & {$[19,31]$} & $x_{32}$ & {$[16,33]$} & $x_{33}$ & {$[24,38]$} \\
\hline$x_{34}$ & {$[34,47]$} & $x_{35}$ & {$[29,40]$} & $x_{36}$ & {$[37,49]$} \\
\hline$x_{37}$ & {$[14,42]$} & $x_{38}$ & {$[35,47]$} & $x_{39}$ & {$[17,40]$} \\
\hline$x_{40}$ & {$[39,50]$} & $x_{41}$ & {$[33,45]$} & $x_{42}$ & {$[29,49]$} \\
\hline$x_{43}$ & {$[29,47]$} & $x_{44}$ & {$[28,47]$} & $x_{45}$ & {$[41,50]$} \\
\hline$x_{46}$ & {$[13,44]$} & $x_{47}$ & {$[34,49[$} & $x_{48}$ & {$[15,44]$} \\
\hline$x_{49}$ & {$[48,50]$} & $x_{50}$ & {$[31,49]$} & & \\
\hline & & & & & \\
\hline
\end{tabular}

Let $w_{0}=(1 / 6,1 / 6,1 / 6,1 / 6,1 / 6,1 / 6)$ be the objective weight vector of attributes. We consider three cases:

Case A. The incomplete attribute weighs set is:

$S=\left\{\left(w_{1}, w_{2}, \ldots, w_{6}\right)^{T} \mid w_{1} \geq w_{2} \ldots \geq w_{6}\right\} ;$

Case B. The incomplete attribute weighs set is:

$S=\left\{\left(w_{1}, w_{2}, \ldots, w_{6}\right)^{T} \mid w_{4}-w_{5} \geq w_{1}-w_{2}\right\} ;$

Case C. The incomplete attribute weighs set is: $S=\left\{\left(w_{1}, w_{2}, \ldots, w_{6}\right)^{T} \mid 0.8 \leq w_{1} / w_{2} \leq 1.2, \quad 0.5 \leq w_{3} / w_{4} \leq 2\right.$,

$\left.0.95 \leq w_{5} / w_{6} \leq 1.05\right\}$.

Model (15) is used to manipulate the strategic weight vector $w^{*}$ so that the desired ranking of different manipulated alternatives, $r^{*}$, is obtained as listed in Table 2 .
Table 2: The strategic weight vector, $w^{*}$, for desired ranking, $r^{*}$, of different manipulated alternatives, $x_{k}$.

\begin{tabular}{c|ccc}
\hline$S$ & $x_{k}$ & $r^{*}$ & $w^{*}$ \\
\hline \multirow{4}{*}{$\begin{array}{c}\text { Case } \\
\text { A }\end{array}$} & $x_{3}$ & 3 & $(0.250,0.166,0.166,0.166,0.166,0.086)$ \\
\cline { 2 - 4 } & $x_{16}$ & 14 & $(0.184,0.167 .0 .167 .0 .167 .0 .165,0.150)$ \\
\cline { 2 - 4 } & $x_{30}$ & 44 & $(0.281,0.281,0.239,0.154,0.045,0)$ \\
\hline \multirow{2}{*}{$\begin{array}{c}\text { Case } \\
\text { B }\end{array}$} & $x_{3}$ & 2 & $(0.150,0.167,0.197,0.167,0.167,0.153)$ \\
\cline { 2 - 4 } & $x_{16}$ & 9 & $(0.167,0.080,0.068,0.386,0.3,001)$ \\
\cline { 2 - 4 } & $x_{30}$ & 11 & $(0,0,0,0.164,0.164,0.671)$ \\
\hline \multirow{3}{*}{$\begin{array}{c}\text { Case } \\
\text { C }\end{array}$} & $x_{3}$ & 3 & $(0.167,0.147,0.187,0.167,0.167,0.167)$ \\
\cline { 2 - 4 } & $x_{16}$ & 14 & $(0.181,0.167,0.153,0.167,0.167,0.167)$ \\
\cline { 2 - 4 } & $x_{30}$ & 10 & $(0,0,0.03,0.06,0.444,0.467)$ \\
\hline
\end{tabular}

\section{CONCLUSION}

This paper focuses on some issues on the strategic attribute weight to manipulate the ranking of alternatives for incomplete information of attribute weights. First, we define the concept of the ranking range of an alternative in the MADM, and propose MLPMs to obtain the ranking range of alternatives and design a strategic attribute weight vector to obtain a desired ranking under incomplete information of attribute weights. A numerical example is used to demonstrate the validity of our models. In the future, we argue that it would be worth investigating the MADM strategic weight manipulation with incomplete information in a group decision and consensus reaching context $[2,3,5,10,16,20]$, as well as the strategic expert-weight manipulation in the group decision making with preference relations $[4,8,9,17,21]$.

\section{REFERENCES}

[1] F.H. Barron, B.E. Barrett, Decision quality using ranked attribute weights, Management Science 42 (11) (1996) 1515-1523.

[2] F.J. Cabrerizo, F. Chiclana, R. Al-Hmouz, A. Morfeq, A.S. Balamash, E. Herrera-Viedma, Fuzzy decision making and consensus: Challenges, Journal of Intelligent \& Fuzzy Systems 29 (3) (2015) 1109-1118.

[3] X. Chen, H.J. Zhang, Y.C. Dong, The fusion process with heterogeneous preference structures in group decision making: A survey, Information Fusion 24 (2015) 72-83.

[4] F. Chiclana, E. Herrera-Viedma, S. Alonso, F. Herrera, Cardinal consistency of reciprocal preference relations: A Characterization of multiplicative transitivity, IEEE Transactions on Fuzzy Systems 17 (1) (2009) 14-23

[5] F. Chiclana, J.M. Tapia Garcia, M.J. Del Moral, E. Herrera-Viedma, A Statistical Comparative Study of Different Similarity Measures of Consensus in Group Decision Making, Information Sciences 221 (2013) 110-123.

[6] D.H. Choi, B.S. Ahn, Eliciting customer preferences for products from navigation behavior on the web: A multicriteria decision approach with 
implicit feedback, IEEE Transactions on Systems, Man, and Cybernetics Part A: Systems and Humans 39 (4) (2009) 880-889.

[7] M. Danielson, L. Ekenberg, Y. He, Augmenting ordinal methods of attribute weight approximation, Decision Analysis 11 (1) (2014) 21-26.

[8] Y.C. Dong, C.C. Li, F. Chiclana, E. Herrera-Viedma, Average-case consistency measurement and analysis of interval-valued reciprocal preference relations, Knowledge-based Systems 114(2016) 108-117.

[9] Y.C. Dong, C.C. Li, F. Herrera, Connecting the linguistic hierarchy and the numerical scale for the 2-tuple linguistic model and its uses to deal with hesitant unbalanced linguistic information, Information Sciences 367-368 (2016) 259-278.

[10] Y.C. Dong, H.J. Zhang, Multiperson decision making with different preference representation structures: A direct consensus framework and its properties, Knowledge-based Systems 58 (2014) 45-57.

[11] Y.C. Dong, H.J. Zhang, E. Herrera-Viedma, Integrating experts' weights generated dynamically into the consensus reaching process and its applications in managing non-cooperative behaviors, Decision Support Systems 84 (2016) 1-15.

[12] Y.C. Dong, H.J. Zhang, E. Herrera-Viedma, Consensus reaching model in the complex and dynamic MAGDM problem, Knowledge-Based Systems 106 (2016) 206-219.

[13] M. Doumpos, C. Zopounidis, A multicriteria decision support system for bank rating, Decision Support Systems 50 (1) (2010) 55-63.

[14] I.N. Durbach, T.J. Stewart, Modeling uncertainty in multi-criteria decision analysis, European Journal of Operational Research 223 (1) (2012) 1-14.

[15] Z.P. Fan, J. Ma, Q. Zhang, An approach to multiple attribute decision making based on fuzzy preference information on alternatives, Fuzzy sets and systems 131 (1) (2002) 101-106.

[16] E. Herrera-Viedma, F.J. Cabrerizo, J. Kacprzyk, and W. Pedrycz, A review of soft consensus models in a fuzzy environment, Information Fusion 17 (2014) (4) 4-13.

[17] E. Herrera-Viedma, F. Chiclana, F. Herrera, and S. Alonso, Group decision making model with incomplete fuzzy preference relations based on additive consistency, IEEE Transactions on Systems, Man, and Cybernetics - Part B 37 (2007) (1) 176-189.

[18] D. Horsky, M.R. Rao, Estimation of attribute weights from preference comparisons, Management Science 30 (7) (1984) 801-822.

[19] S.H. Kim, S.H. Choi, J.K. Kim, An interactive procedure for multiple attribute group decision making with incomplete information: Rangebased approach, European Journal of Operational Research 118 (1) (1999) 139-152.

[20] C.C. Li, Y.C. Dong, F. Herrera, E. Herrera-Viedma, L. Martínez, Personalized individual semantics in computing with words for supporting linguistic group decision making, An application on consensus reaching, Information Fusion 33 (2017) 29-40.

[21] W.Q. Liu, Y.C. Dong, F. Chiclana, F.J. Cabrerizo, E. Herrera-Viedma, Group decision-making based on heterogeneous preference relations with self-confidence, Fuzzy Optimization and Decision Making, in press, DOI 10.1007/s10700-016-9254-8.

[22] A. Ishizaka, P. Nemery, Multi-criteria decision analysis: methods and software, John Wiley \& Sons 2013.

[23] I. Palomares, L. Martínez, F. Herrera, A consensus model to detect and manage noncooperative behaviors in large-scale group decision making, IEEE Transactions on Fuzzy Systems 22 (3) (2014) 516-530.

[24] K.S. Park, K.S. Lee, Y.S. Eum, K. park, Extended methods for identifying dominance and potential optimality in multi-criteria analysis with imprecise information, European Journal of Operational Research 134 (3) (2001)557-563.

[25] D. Pekelman, S.K. Sen. Mathematical programming models for the determination of attribute weights, Management Science 20 (8) (1974) 1217-1229.

[26] D.A. Pelta, R.R. Yager, Decision strategies in mediated multiagent negotiations: an optimization approach, IEEE Transactions on Systems, Man, and Cybernetics Part A: Systems and Humans 40 (3) (2010) 635640 .
[27] R. Roberts, P. Goodwin, Weight approximations in multi-attribute decision models, Journal of Multi-Criteria Decision Analysis 11(6) (2002) 291-303.

[28] Shanghai Jiao Tong University, Academic Ranking of World Universities, http://www.arwu.org / 2016-8-15.

[29] J. Wallenius, J.S. Dyer, P.C. Fishburn, R.E. Steuer, S. Zionts, and K. Deb, Multiple criteria decision making, multiattribute utility theory: Recent accomplishments and what lies ahead, Management Science 54 (7) (2008) 1336-1349.

[30] R.R. Yager, Defending against strategic manipulation in uninorm-based multi-agent decision making, European Journal of Operational Research 141 (1) (2002) 217-232.

[31] R.R. Yager, Penalizing strategic preference manipulation in multi-agent decision making, IEEE Transactions on Fuzzy Systems 9 (3) (2001) 393-403.

[32] K. Yoon, C.L. Hwang, Multiple attribute decision making: methods and applications, Springer, Berlin 1981.

\section{APPENDIX A: PROOF}

Proof of Lemma 1:

(i): Necessity: Suppose that $x_{i} x_{j}$ and $D\left(x_{i}\right) \leq D\left(x_{j}\right)$. On the one

hand, this means that for any $k$ such that $D\left(x_{k}\right) \geq D\left(x_{j}\right)$, we would have that $D\left(x_{k}\right) \geq D\left(x_{i}\right)$, i.e., it would be $Q_{j} \subseteq Q_{i}$, and therefore it is $r\left(x_{j}\right) \leq r\left(x_{i}\right)$, which contradicts that $x_{i} x_{j}$.

Sufficiency: If $D\left(x_{i}\right)>D\left(x_{j}\right)$, on the one hand, this means that for any $k$ such that $D\left(x_{k}\right)>D\left(x_{i}\right)$, we would have that $D\left(x_{k}\right)>D\left(x_{j}\right)$, i.e., it would be $Q_{i} \subseteq Q_{j}$. On the other hand, it is $x_{i} \in Q_{j}$. Because $x_{i} \notin Q_{i}$, we have $Q_{i} \subset Q_{j}$, and therefore it is $r\left(x_{i}\right)<r\left(x_{j}\right)$, i.e., $x_{i} \quad x_{j}$

(ii): The proof is similar to proof of (i).

This completes the proof of Lemma 1 .

\begin{tabular}{ccccccc}
\multicolumn{7}{c}{ APPENDIX B: THE DATA FOR 50 UNIVERSITIES } \\
\hline$x_{i}$ & $v_{i 1}$ & $v_{i 2}$ & $v_{i 3}$ & $v_{i 4}$ & $v_{i 5}$ & $v_{i 6}$ \\
\hline 1 & 100 & 100 & 100 & 100 & 100 & 79.2 \\
2 & 42.9 & 89.6 & 80.1 & 73.6 & 73.1 & 55.8 \\
3 & 65.1 & 79.4 & 64.9 & 68.7 & 68.4 & 59 \\
4 & 78.3 & 96.6 & 51.3 & 56.7 & 67.8 & 58.5 \\
5 & 69.4 & 80.7 & 55.3 & 71.7 & 61.7 & 69.7 \\
6 & 53.3 & 98 & 51.3 & 47.2 & 42.9 & 74.4 \\
7 & 49.7 & 54.9 & 56.2 & 55 & 74.5 & 46.1 \\
8 & 51 & 66.7 & 39.7 & 57.3 & 43.6 & 100 \\
9 & 63.5 & 65.9 & 41 & 53.3 & 68.9 & 33.3 \\
10 & 59.8 & 86.3 & 34 & 42.7 & 50.2 & 44.5 \\
11 & 47.6 & 50.4 & 44.7 & 58.4 & 62.6 & 37.1 \\
12 & 29.5 & 47.1 & 58 & 44.5 & 71.4 & 33.4 \\
13 & 42 & 49.8 & 41 & 47 & 60.5 & 40.9 \\
14 & 19.2 & 35.5 & 49.2 & 57.8 & 63.5 & 37 \\
15 & 21.2 & 31.6 & 49.2 & 52.1 & 72.6 & 31 \\
16 & 37.7 & 33.6 & 38.4 & 47 & 71.9 & 31.1 \\
17 & 28.1 & 36.2 & 41 & 41.6 & 73.9 & 32.4 \\
\hline
\end{tabular}




\begin{tabular}{ccccccc}
\hline 18 & 31.6 & 33.8 & 42.3 & 39.4 & 67.7 & 37.8 \\
19 & 29.5 & 35.5 & 35.5 & 50.2 & 55.6 & 46.1 \\
20 & 36.3 & 25.3 & 30.8 & 47.5 & 70 & 29.7 \\
21 & 0 & 39.9 & 37 & 52.1 & 59.3 & 33.5 \\
22 & 14.5 & 35.8 & 43.5 & 32.9 & 64 & 39.9 \\
23 & 34.4 & 0 & 51.3 & 41.6 & 76.6 & 25.8 \\
24 & 34.4 & 24.9 & 51.3 & 42 & 51.7 & 37.2 \\
25 & 15.4 & 19.2 & 57.1 & 38.9 & 62.1 & 25.9 \\
26 & 15.4 & 22.1 & 54.3 & 35.6 & 59.6 & 32.8 \\
27 & 19.9 & 17.2 & 32.4 & 38.2 & 80.1 & 30.3 \\
28 & 32.8 & 34.8 & 30.8 & 35 & 62.7 & 24.3 \\
29 & 28.1 & 31.9 & 32.4 & 39.5 & 57.3 & 22 \\
30 & 21.8 & 18.8 & 32.4 & 36.2 & 65.2 & 41.9 \\
31 & 29.9 & 36.2 & 30.8 & 33.1 & 55.1 & 29.1 \\
32 & 31.6 & 37.2 & 27.1 & 31.5 & 58.4 & 23.8 \\
33 & 29.5 & 16.3 & 39.7 & 32.5 & 64.8 & 24.1 \\
34 & 15.4 & 18.8 & 42.3 & 32.7 & 64.5 & 27.2 \\
\hline
\end{tabular}

\begin{tabular}{ccccccc}
\hline 35 & 18.5 & 32.6 & 37 & 26.4 & 58.4 & 29 \\
36 & 8.9 & 23.7 & 39.7 & 32.6 & 60.8 & 33.8 \\
37 & 17 & 59.8 & 27.1 & 41.8 & 19.3 & 40 \\
38 & 12.6 & 34.1 & 30.8 & 36.8 & 46.2 & 35.1 \\
39 & 33.6 & 27.4 & 20.5 & 29.7 & 61.9 & 25.3 \\
40 & 17 & 13.3 & 35.5 & 24.8 & 67.9 & 32.2 \\
41 & 20.5 & 24.9 & 32.4 & 31.3 & 52.1 & 26.8 \\
42 & 14.5 & 39.1 & 32.4 & 27.3 & 37.7 & 38.2 \\
43 & 18.5 & 34.5 & 30.8 & 37.6 & 34.9 & 27.7 \\
44 & 25.6 & 26.6 & 22.9 & 25.1 & 52.6 & 40.2 \\
45 & 16.2 & 16.3 & 29 & 37 & 56.3 & 26.6 \\
46 & 30.3 & 54.3 & 10.3 & 17.6 & 47.9 & 27.7 \\
47 & 19.9 & 25.3 & 22.9 & 30.6 & 51.8 & 34.9 \\
48 & 34.8 & 21.6 & 29 & 23.3 & 49.7 & 34.6 \\
49 & 0 & 31.7 & 35.5 & 23.4 & 53.9 & 26.2 \\
50 & 21.2 & 21 & 34 & 19.6 & 55.3 & 27.9 \\
\hline
\end{tabular}

